\title{
Design and Application of Intelligent Library Access Control System of University
}

\author{
Zhuorui Sun, Rende $\mathrm{Li}^{*}$ \\ Library, University of Shanghai for Science and Technology \\ Shanghai, 200093, China \\ *Email: lirende@usst.edu.cn
}

\begin{abstract}
Traditional university library access control system has its limitation which will cause, which students often get locked in the library by accident. In order to reduce the occurrence of this phenomenon, this article introduces an intelligent university library access control system. We clarify the implementation of the intelligent university library access control system, and use a library control system as an example, by designing a multi-sector system scheduling management application process suitable for the education system. This system has the advantages of intelligence, modularity, interactivity, perfectibility, and generalizability. The system can realize the intelligent upgrade of the university library access control system, responding to the graded incidents such as trapped students and other emergencies, and improve the library service quality and readers' satisfaction.
\end{abstract}

Keywords: University library, Access control system, Intelligence

\section{INTRODUCTION}

One of the symbols of a country's true rise is the improvement of the national cultural quality, and the fundamental way to improve national cultural quality is to improve the quality of education. Therefore, in recent years, the state has increased its investment in infrastructure in universities. The teaching land in universities has continued to expand, and teaching buildings have been continuously renovated and refurbished. Among them, as the cultural exchange center of universities, the libraries with rich academic resources have also become major investment targets for universities.

With the expansion of the occupied area, newly built university libraries have adopted the duolex design in the internal structure in order to effectively improve the use efficiency per unit area.

Although such a design is artistic, it increases the time and difficulty for librarians to inspect the library. At present, the human resources of university libraries are relatively tight. Usually only one or two librarians are responsible for one floor. However, the function of the current access control system is limited. In the peak period of people leaving the library before it closed, accidents in which students are locked in stacks or reading rooms often occur. In order to avoid the frequent occurrence of such incidents and to ensure the safety of students during school, it is necessary to optimizing the library access control monitoring system. This has made a tremendous contribution to the scientific management of libraries, to the improvement of library service, to the optimal allocation of library resources and to the effective protection of library and reader safety ${ }^{[1]}$.

\section{DESIGN AND APPLICATION OF INTELLIGENT LIBRARY ACCESS CONTROL SYSTEM}

\section{A. System Implementation}

The entire system consists of a central processing unit, an auxiliary signal transmission unit, a network signal transmission unit, a signal unit of the security office, and an access control unit. The auxiliary signal transmission unit is responsible for receiving instructions transmitted by the on-duty librarian through the computer and transmitting the instructions to the central processing unit. At the same time, it can also receive and process the execution instructions sent by the central processing unit and other systems that need to be linked with the system. The central processing unit is the core of the whole system. It receives the signals from different sources to judge the situation occurring on the site and sends related commands to other systems linked with the system according to the preset program or sends help signal through the network signal transmission unit to the security department. The network signal transmission unit sends help information to different levels of contacts respectively according to different levels of assistance by receiving signals from the central processing unit. The security department signal unit sends the corresponding action instructions to the security staff and records them by receiving the signal from the central processing unit. The access control unit is composed of different modules according to the actual situation of the library. Modules cannot communicate with each other. When multiple modules send signals at the same time, signals are sent to the central processing unit in sequence according to the different priority levels of different modules during installation. The overall structure is shown in Fig.1. 


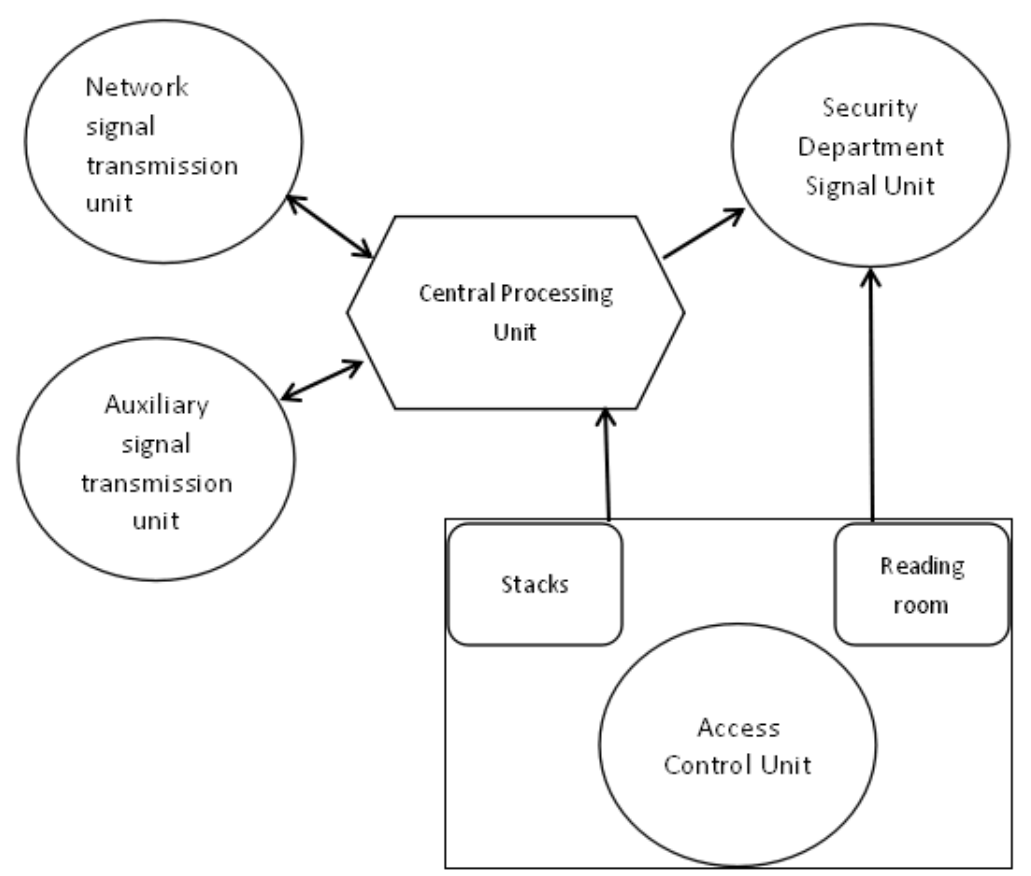

Fig.1. Overall structure diagram of intelligent library access control system

\section{B. Application of Intelligent University Library Access Control System}

Starting from the aspects of prevention and control, improving the library's internal control program, respond in a timely manner, and process it in a hierarchical manner. Try to minimize the occurrence of students locked in the library after it closed. Time to find a solution to ensure student safety and library property safety, and find a solution in the first time after similar incidents, to ensure students' personal safety and library property safety.

- Prevention: The on-duty teacher sends a closed instruction to the central processing unit through the computer 10 minutes before the off duty. After receiving the instruction, the CPU sends an instruction to the broadcast and lighting system linked with the system through the auxiliary signal transmission unit, and broadcasts the closed music through the broadcast. The voice broadcast reminds the students to leave the library as soon as possible, and the indicator light of the leaving flashes at the same time to remind the students in the hall with the sound and light signals. The central processing unit sends an instruction to the infrared alarm device that is linked with the system through the auxiliary signal transmission unit after 10 minutes of timekeeping, and infrared rays are scanned to ensure that there are no students left in the library. If there are any remaining students, the Central Processing Unit will send instructions to the on-duty teacher and security department to remind the teacher and related staff to go to the site and arrange for the students to leave.

- Control: How to make up for the omission of the system is an important standard to test whether the system is perfect ${ }^{[2]}$. In this system, if a student is unfortunately locked in the library, first he needs to find the access control system on the door. The access control system sets different security levels and priorities according to different installation positions, such as the reading room, stacks etc., for the central processing unit to prioritize the use of signals when signals are issued at the same time ${ }^{[3]}$. The hardware part of the access control system consists of a numeric keypad and a contactless swipe card reader. The locked student swipes his own campus card on the swipe reader, the access control system transmits the signal to the central processing unit. The central processing unit is based on the students who are locked, different locations execute different handlers.

1) Students locked in the reading room: The central processing unit sends the signal to the security office, and the security staff manually enters the door-opening instructions to rescue the trapped student. After the student leaves the reading room, the door is automatically closed and a closed door completion signal is sent to the security and the central processing unit. If the central processing unit does not receive the closed door completion signal within 3 minutes after the door opening command is issued, the command is sent to the security and reminded the security to check the locks in the reading room.

2) Students locked in the stacks: The central processing unit sends the signal to the security office and at the same time prompts the department director/deputy curator's mobile terminal through the network signal transmission unit. The department director/deputy curator sends the password command to the central processing unit through the mobile terminal. Password consists of two groups of six digits which sent by the central processing unit to the 
mobile phones of the security office and the trapped student. After security staff received the password, they went to the on-site access control office. Security staff and trapped students opened the door after entering the password through the access control system. At the same time, the security staff checks the trapped student to ensure that the student did not carry any prohibited items out of the library.

\section{Advantages of the System}

1) Intelligent: There are different treatment options for the location of the trapped students to ensure that the trapped students are rescued in the shortest time ${ }^{[4]}$

2) Modularity: All components of the system are in the form of modules, which can be added or reduced as needed, and can be added/reduced after installation ${ }^{[5]}$.

3) Interactivity: Different schools have different management systems ${ }^{[6]}$, and good human-computer interaction can be modified and adjusted through the terminal installed on the computer ${ }^{[7]}$ to better match the management model of the user.

4) Perfectibility: Through the multi-hierarchy management model, while ensuring that the trapped students are rescued at the first time and safeguarding the property of the library.

5) Generalizability: This system is not only applicable to libraries, but can be extended to various large public places by correcting some procedures.

\section{CONCLUSION}

The efficient, convenient, and safe library service can attract more readers to use the library, increase readers' stickiness, and maximize the value of the library ${ }^{[8]}$. At present, access control system in most colleges and universities only has basic functions such as user identification and prompting. For the current situation of the development of university libraries, the application of intelligent access control system is imperative. Introducing the intelligent access control system in the university library can provide readers with more convenient and comfortable entrance experience. It is very useful for improving the library's service quality, work efficiency and management effectiveness, and it can also better realize the modernization of the library's scientific management ${ }^{[9]}$.

\section{ACKNOWLEDGMENT}

This work is supported by University of Shanghai for Science and Technology (Grant No. 18HJ-DSDG-ZD-004).

\section{REFERENCES}

[1] Sipe, V. (2017). Association for Library Collections and Technical Services Annual Report 2016-17. Library Resources \& Technical Services, 61(4), 180-182.

[2] Im, H., Lee, J., \& Park, J. (2016). A rhythm-based access control system for secure wellness services. Journal Of Supercomputing 72 (7), 2860-2873. doi:10.1007/s11227-016-1642-x

[3] Bedi, P., Kaur, H., \& Gupta, B. (2014). Trust-based access control for collaborative systems. Journal Of Experimental \& Theoretical Artificial Intelligence, 26(1), 109-126. doi:10.1080/0952813X.2013.813973

[4] Ai, H., \& Cheng,X.( 2018). Research on embedded access control security system and face recognition system."Measurement (02632241) 123, 309-322. doi:10.1016/j.measurement.2018.04.005

[5] TIAN, Z., WANG, Y., WANG, J., CHEN, H., \& ZHAO, Y. (2014). Design of Multi-door Access Control and Real-time Image Acquisition System. Research \& Exploration In Laboratory, 33(8), 37-40.

[6] Wang, J., Chin, Y., Hsieh, W., Lin, C., Chen, Y., \& Siahaan, E. (2015). Speaker Identification With Whispered Speech for the Access Control System. IEEE Transactions On Automation Science \& Engineering, 12(4), 1191-1199. doi:10.1109/TASE.2015.2467311

[7] Ardagna, C. A., Cremonini, M., Di Vimercati, S. C., \& Samarati, P. (2008). A privacy-aware access control system. Journal Of Computer Security, 16(4), 369-397. doi:10.3233/JCS-2008-0328

[8] Dahan, S. M., Taib, M. Y., Zainudin, N. M., \& Ismail, F. (2016). Surveying Users' Perception of Academic Library Services Quality: A Case Study in Universiti Malaysia Pahang (UMP) Library. Journal Of Academic Librarianship, 42(1), 38-43. doi:10.1016/j.acalib.2015.10.006.

[9] Maddox, A., \& Linlin, Z. (2017). University Library Strategy Development: A Conceptual Model of Researcher Performance to Inform Service Delivery. New Review Of Academic Librarianship, 23(2/3), 125-135. doi:10.1080/13614533.2017.1342673. 